\title{
Will the Department of Health and the Minister make the same mistake twice?
}

To the Editor: In the early 1990s, a landmark decision was made by the South African Nursing Council (SANC), and supported by the Department of Health, to close down all adult-education vocational-training nursing colleges in favour of higher education (HE) institutions.

Fast-forward 20 years and this 'well-meaning' decision has now plunged South Africa (SA) into its largest shortage of trained nurses in history, referred to in many newspapers and press reports as the 'crisis in nursing. Even the Minister of Health $(\mathrm{MoH})$ and the Health Professions Council of SA (HPCSA) have admitted that the closing of nursing colleges was a huge mistake. As a result, many previously closed colleges have been reopened in a desperate attempt to supply our hospitals with trained nursing staff, at a multi-million Rand cost to the taxpayer.

Emergency medical services (EMS) are about to follow the same disastrous path. The governing board of the HPCSA, controlling training of all SA ambulance personnel, has set out a policy stating that the current vocational training for ambulance staff will be closed down and replaced by HE courses. The HPCSA has gone to great lengths to convince the $\mathrm{MoH}$ that closure of the vocational programmes will benefit all involved. Their (flawed) rationale is exactly the same as that of the SANC almost 20 years ago.

This decision by the HPCSA holds no merit since the current vocational qualification allows a paramedic to exit, fully qualified, after a minimum of 36 months training equal to that of the HE National Diploma Adult Education and Training (AET) course, but vastly exceeding it in terms of practical, in-service medical training.

The original aim in establishing the HE National Diploma AET course was to improve the standard of care provided to the patient and eventually to phase out vocational training once the country had graduated a sufficient number of trained medics.

Very little effort has been taken by the HPCSA to align short courses to the National Qualifications Framework (NQF) despite the fact that the vast majority of ambulance staff (approximately 97\%) hold vocational qualifications. For the past 8 years, the top positions on the Professional Board (PBEC) of the HPCSA, in fact, have all been held by individuals representing only the HE institutions, with none of the vocational institution having representation.

Should the HPCSA and the MoH go ahead with promulgating these regulations, the same decline in qualified ambulance staff, exactly as happened with nursing staff, would be set in motion. 
Ultimately the public will be adversely affected. When there are not enough trained medics in EMS, ambulances will be forced, quite simply, to stop responding to calls and people will die.

\section{Clint Cronning}

BAA course coordinator, Ambutek, Cape Town, South Africa

clint@ambutek.co.za

S Afr Med J 2013;103(8):499-500. DOI:10.7196/SAMJ.6957 